\title{
How are Educational Researchers Interacting with End-users to Increase Impact?
}

\author{
Amanda Cooper
}

\begin{abstract}
There has been increased interest in how researchers might collaborate with end users to increase the impact of their work. In Canada, efforts to extend research impact beyond academia are called knowledge mobilization (KMb). This study surveyed SSHRC- funded educational researchers to assess their $\mathrm{KMb}$ efforts in relation to three areas: stakeholder engagement (target audience and frequency of interaction), dissemination mechanisms (intermediaries, networks, media, online tools), and research impact (research-related, service/practice, policy, societal). Findings: 70\% of researchers reported regularly interacting with target audiences. Types of interactions included getting to know target audiences $(71 \%)$, discussing research results $(65 \%)$, and dedicating resources for capacity building (45\%). Researchers reported impacts in relation to research $(76 \%)$, service/practice (67\%), and policy (35\%), and societal impacts (35\%). Researchers felt very well prepared to create plain language summaries of their work (54\%), and collaborate with stakeholders $(45 \%)$, but much less prepared to deal with media $(32 \%)$, work with intermediaries $(22 \%)$, or use technology to disseminate their work $(16 \%)$. Implications for engaged scholarship are articulated in five areas: prioritization and co-production; packaging and push; facilitating pull; exchange; and improving climate for research use by building demand.
\end{abstract}

KEYWORDS research impact, research evaluation, engaged scholarship, knowledge mobilization

The context of research and its evaluation in social systems has changed considerably in the past two decades. The rise of research impact agendas globally has increased interest in how researchers collaborate with non-academic audiences to increase the impact of their work (Cuthill, 2010; Hicks, 2012; Phipps, Cummings, Pepler, Craig, \& Cardinal, in press). Alongside the rise of the research impact agenda has been a global interest in the field of knowledge mobilization (KMb) (Nutley, Walter, \& Davies, 2007). KMb is about how research finds its way (or fails to find its way) into the hands of those in communities that could benefit from its use. There is a widely acknowledged gap between research and both policy and practice across sectors (Davies, Nutley, \& Smith, 2000; Hemsley-Brown, 2004; Lemieux-Charles \& Champagne, 2004; Pfeffer \& Sutton, 1999). Research often fails to have the impact it might, due to a lack of capacity to translate this work for end-users in non-academic settings and mobilize policymakers, practitioners, and community members to apply its findings. Due 
to this well-documented problem, there has been an increased focus on KMb sectors. The rationale for prioritizing $\mathrm{KMb}$ is persuasive. Historical applications of evidence in countless areas of social policy have seen improved outcomes and benefits for citizens in society (such as handwashing in health, use of seatbelts in transportation, anti-smoking legislation in certain jurisdictions such as Canada, among many others). This article explores these issues using theoretical perspectives and conceptualization from KMb and engaged scholarship (outlined more fully in the literature review) and presents data from a survey of Canadian researchers exploring their interactions with educational stakeholders, their level of preparedness for collaborating with non-academic audiences, and the perceived impact of their funded research projects in four areas: research-related impacts, practice impacts, policy impacts, and broader societal impacts.

\section{Literature Review}

This literature review is organized according to the major themes arising from the literature on KMb: stakeholder engagement, dissemination mechanisms, and research impact. The review begins by discussing the foundations of engaged scholarship using Boyer's (1990) seminal work on scholarship reconsidered and its implications for stakeholder engagement, before discussing how $\mathrm{KMb}$ is being conceptualized and operationalized in national research infrastructure around the globe. Next, we outline dissemination mechanisms that researchers can use to carry out new mandates to reach broader audiences, including intermediary organizations (bridging organizations that facilitate connections between research producers and user communities), media, and web-based platforms. The final section explores research impact by adapting a framework from the health sector (Kuruvilla, Mays, Pleasant, \& Walt, 2006) that categorizes impacts in four areas: research, service (practice), policy, and society.

\section{Defining knowledge Mobilization, Engaged Scholarship and Implications for Stakeholder Engagement}

Traditional academic outputs, such as peer-reviewed journal articles, are failing to have impact outside of academia (Nutley et al., 2007; Wixted \& Beaudry, 2012). Boyer's (1990) seminal work Scholarship Reconsidered: Priorities of the professoriate argued that academic priorities and traditional research need to be broadened:

Knowledge is not necessarily developed in... a linear manner. The arrow of causality can, and frequently does, point in both directions. Theory surely leads to practice. But practice also leads to theory....viewed from this perspective, a more comprehensive, more dynamic understanding of scholarship can be considered. (pp.15-16)

Boyer (1990) suggested four areas important to his conception of scholarship: discovery (original empirical work that advances societal knowledge), integration (synthesis across disciplines, across topics or across time), application (later termed "scholarship of engagement") which involves faculty members working outside the university with communities and non-academic 
audiences, and teaching and learning (study of teaching and learning processes) (Figure 1).

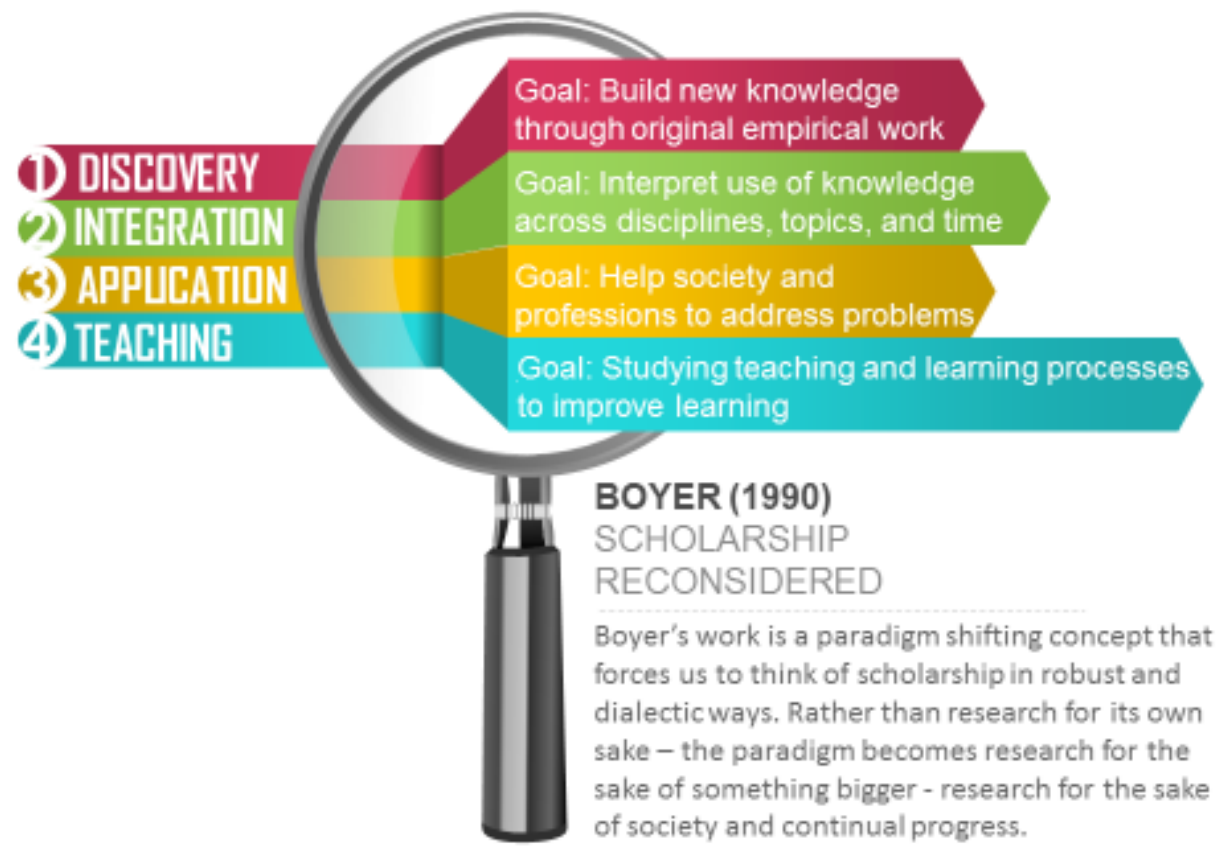

Figure 1: Scholarship reconsidered: Discovery, integration, application, and teaching

Boyer's work fundamentally shifted the way many scholars began conceptualizing the role of scholarship as moving beyond research and academic publications. Boyer's vision of the professoriate incorporated the idea of academics as public intellectuals with an important role to play in societal improvement efforts. In many ways, the KMb and research impact movements (if one accepts the underlying spirit of these movements as societal transformation) echo Boyer's notions of the role of scholarship beyond the ivory tower. The Social Sciences and Humanities Research Council of Canada (SSHRC) is the primary funder of social science research in the nation. SSHRC has increasingly been prioritizing knowledge mobilization $(\mathrm{KMb})$ and partnerships (through various partnership development grants and connections grants). SSHRC defines KMb as follows:

Knowledge mobilization: The reciprocal and complementary flow and uptake of research knowledge between researchers, knowledge brokers and knowledge users - both within and beyond academia - in such a way that may benefit users and create positive impacts within Canada and/or internationally, and, ultimately, has the potential to enhance the profile, reach and impact of social sciences and humanities research. (SSHRC, 2014) 
The increased emphasis by research funders on non-academic engagement and impact is shifting the way researchers conceptualize and go about their work. A more recent iteration of this goal is the emerging field of engaged scholarship:

\begin{abstract}
Engaged scholarship (defined as a form of collaborative inquiry between academics and practitioners that leverages their different perspectives to generate useful knowledge) is based on the belief that higher-quality, more relevant research results from true collaboration and from integrating the diverse perspectives of multiple stakeholders. (Bowen \& Graham, 2013, p.12)
\end{abstract}

Many funders across the globe are changing the way they talk about research, its goals, and its ultimate impact. And most are moving towards conceptions of multi-stakeholder collaboration in the pursuit of greater research impact. The rationale behind the move to collaborative networks of diverse stakeholders is that research has failed to have the impact it might, due to a lack of involvement of relevant end-users throughout various stages of the research, dissemination, and implementation processes (Cooper, Levin, \& Campbell, 2009; Mitton, Adair, Mckenzie, Patten, \& Perry, 2007; Nutley et al., 2007).

End-users have the potential to inform various aspects of the research process: from shaping what questions are asked and interpreting research results in relation to a specific context or user group, to providing input on what messages and modalities are best suited to a particular target audience (Cuthill, 2010; Martin, 2010; Muirhead \& Woolcock, 2008; Paynter, 2014; Saija, 2014). In light of these developments, it is important to explore the ways in which researchers are engaging target audiences of their research, the dissemination mechanisms they utilize to reach audiences outside the academy, and their perceptions of the impact of these efforts on policy, practice and broader society.

\title{
Dissemination Mechanisms
}

Exploring research dissemination and utilization is not new (Knott \& Wildavsky, 1980; Weiss, 1979), despite recent coinages of terms such as KMb or engaged scholarship that provide more robust understandings of how to co-create research impact (to be further discussed in the next section). Lavis, Ross, McLeod, and Gildiner (2003) categorize KMb processes as follows: producer push, user pull, and exchange. Producer push refers to efforts undertaken by researchers and universities (the producers of research) and includes publications and related products that might increase research use among end-users. User pull refers to efforts that are initiated by intermediary organizations, researchers, or by the practice organizations to build systems and processes for end-users to find, evaluate, share, and apply research in professional contexts. Exchange efforts include collaboration of stakeholders (researchers, policymakers, practitioners) with two-way exchange from researcher-user, but also from user-researcher, in order to address the issues lamented in the field of research as being largely irrelevant to policy and practice spheres in common academic formats (journal articles). Exchange efforts refer to the collaboration of stakeholders (researchers, policymakers, practitioners), a process which 
moves in two directions: from the researcher to the user and from the user to the researcher. Such a two-way exchange can address the irrelevance of much of the research that appears in common academic formats (journal articles) for policies and practices in the fields which are the object of the research. It is important to consider the usefulness of various dissemination mechanisms if we are to learn more about which $\mathrm{KMb}$ processes have the potential to yield the most impact with end-users.

Mechanisms for dissemination are changing rapidly with advancements in technology, and also with the emergence of social media. However, little is known about the frequency with which researchers use media and online dissemination mechanisms for their work. A study by Edelstein, Shah, and Levin (2012) found that

although the internet has become a primary access point for research.... online uptake of research is not as robust as might be thought. Passive strategies of information provision do not, based on these data, seem very effective or efficient, and our findings suggest that organizations interested in sharing research need more active knowledge mobilization strategies. (p.11)

Because online dissemination mechanisms do not necessarily have a wide reach and impact, $\mathrm{KMb}$ scholars suggest that intermediary organizations (third party educational organizations that act as bridges between research producers and users) could improve KMb efforts through tailoring research products for target audiences, facilitating embedded service learning, and through many other functions that seek to make research more engaging, accessible, and useful to end-users (Cooper, 2013). We were interested in learning whether or not researchers were working with intermediary organizations to increase their $\mathrm{KMb}$ efforts and in what capacities.

\section{Research Impact}

Research impact is an important focus of $\mathrm{KMb}$; the rationale underpinning the $\mathrm{KMb}$ movement is that research should positively affect the daily activity of professionals working in public services. There have been some attempts to develop frameworks to measure research impact in the health sector (e.g., Kitson, Harvey, \& McCormack, 1998; Kuruvilla et al., 2006; Lavis, Ross, McLeod, \& Gildiner, 2003). Kuruvilla et al. (2006) provided a catalogue of potential impacts from research in the health sector grouped into four categories: research-related impacts, policy impacts, service impacts, and societal impacts (Figure 2). 


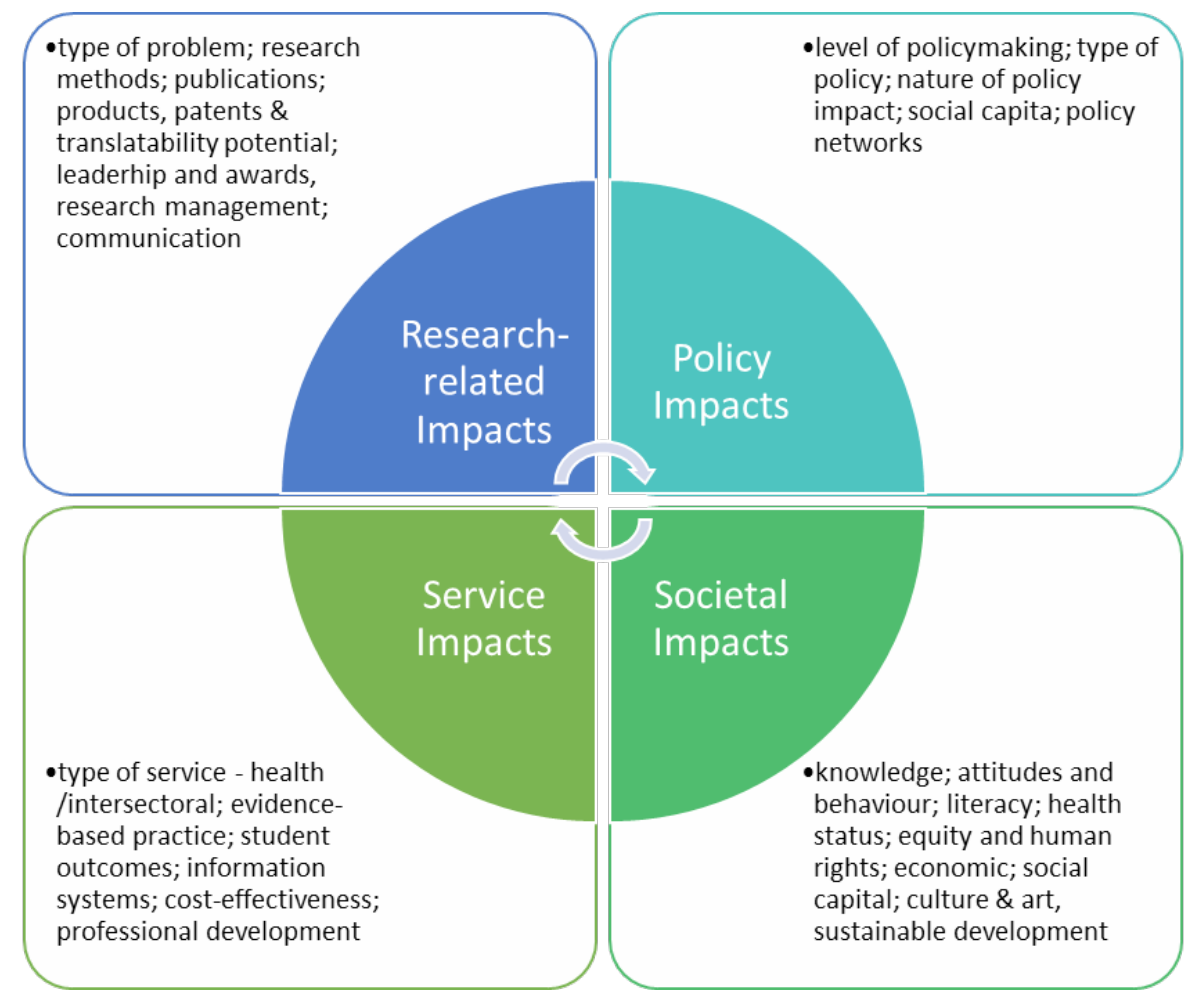

Figure 2: Conceptualizing research impact in public services (adapted from Kuruvilla et al., 2006)

Canadian researchers were surveyed about the perceived effects of their work using Kuruvilla's impact categories modified for education and asked researchers to provide examples of these impacts where possible.

\section{Methods}

Keeping their names and purpose hidden, the team surveyed SSHRC-funded researchers in Canada holding grants related to education in order to assess researchers' interaction with endusers, proportion of time spent on academic versus non-academic outreach and dissemination mechanisms used in relation to intermediaries, media and web-based tools.

\section{Conceptual Framework and Research Questions}

The conceptual framework identifies three areas mentioned in the literature that were explored in relation to researchers' $\mathrm{KMb}$ efforts: stakeholder engagement (target audiences, frequency of interaction), dissemination mechanisms (intermediaries, networks, media, online tools), and impact (research-related, service, policy, societal) in relation to $\mathrm{KMb}$ efforts in relation to academic and non-academic outreach and production (Figure 3). 


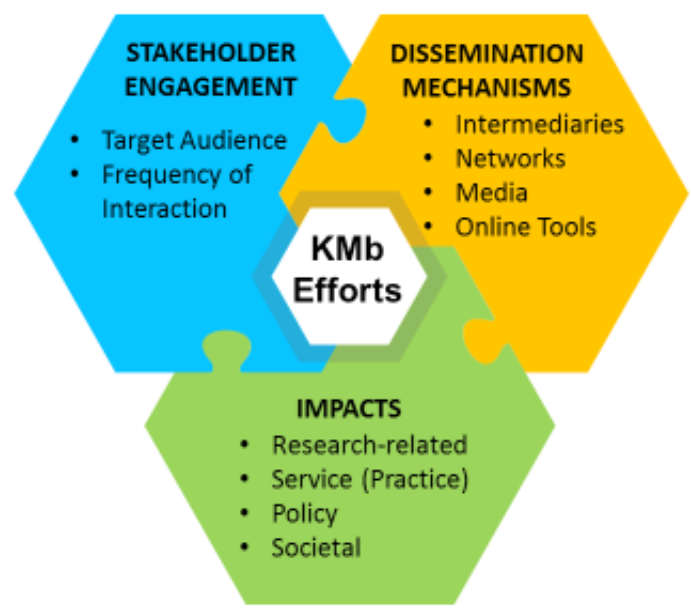

Figure 3: Conceptual framework to explore $\mathrm{KMb}$ efforts of Canadian researchers

The overarching research question was "What KMb efforts are being made by Canadian education researchers to make their findings more accessible and available to the broader education community?" Table 1 articulates further research questions in relation to each section of the conceptual framework.

\section{Sampling and Recruitment}

The sample was identified from the online SSHRC database of successful grant holders using the following parameters: (i) Program - Standard Research Grants, (ii) Discipline - Education, and (iii) Projects completed no later than 2011. Deleting duplications, 278 researchers were identified by the sampling strategy. It was important that grants had been completed a minimum of five years before, since the literature suggests that impact takes time after the completion of a project.

Table 1. Research questions linked to the conceptual framework

\begin{tabular}{ll}
\hline Conceptual Framework Dimension & Research Questions \\
\hline Stakeholder Engagement & What educational stakeholders do researchers \\
& believe their research is most relevant for? \\
& What is the nature and frequency of interaction \\
& with target audiences? \\
& How much time do researchers spend on \\
& academic versus non-academic products, events, \\
& and networks?
\end{tabular}




\begin{tabular}{ll}
\hline Conceptual Framework Dimension & Research Questions \\
\hline Dissemination Mechanisms & How prepared do researchers feel to engage \\
& in different types of non-academic outreach \\
& activities? \\
& What dissemination mechanisms are researchers \\
& using in education? \\
& How do researchers' perceive the impacts \\
Impacts & (research-related, policy, service and societal \\
& impacts) of their work? \\
\hline
\end{tabular}

Our team (working anonymously) hoped that sampling already completed projects would mean that researchers would have published the findings from the final years of their study, and would have a more comprehensive understanding of whether or not uptake had occurred through the various dissemination mechanisms they had employed.

\section{Data Collection and Analysis}

The survey included a demographic section as well as sections corresponding to the conceptual framework on stakeholder engagement, dissemination mechanisms, research impact, and $\mathrm{KMb}$ efforts more broadly including questions relating to academic versus non-academic efforts (link to survey removed for blinding). After survey construction, face validity was assessed through piloting the survey with a small group of researchers and key informants from the field of $\mathrm{KMb} / \mathrm{KT}$ who had expertise (Eisenhart \& Howe, 1992). Recommendations were integrated into the survey. The survey was not implemented multiple times; hence, reliability measures were not ascertained. The survey had face and content validity as a measure of $\mathrm{KMb}$ activity of Canadian researchers; however, I am unsure of its reliability (consistency of a survey's measurement) (Eisenhart \& Howe, 1992). An online survey was distributed by email to the list of 278 researchers compiled from the SSHRC database. Four email reminders were sent to increase the response rate. Ninety-seven respondents chose to participate in the study from across Canada, a 35\% response rate, which is average for an online survey (Kittleson, 1995). Criterion validity was not provided because each survey question and variable asked about discrete and unique items; hence, a particular concept was not distributed throughout the survey. Survey results were exported into Excel for cleaning and then transferred into SPSS to calculate descriptive statistics (i.e., means, medians, standard deviations, range). Qualitative responses from the survey (such as the descriptions of research impact) were imported and analyzed in NVivo. Thematic coding was conducted using areas from conceptual framework (such as Kuruvilla's four impact categories) and inductively in relation to common themes emerging (such as researchers identifying that impact occurs over time).

\section{Findings}

Educational researchers are involving stakeholders in various ways in their research projects 
(such as getting to know their target audiences and discussing research results), with many reporting regular interactions with end users. Most educational researchers $(72 \%)$ report that teachers are the target audience that is most relevant for their work. Researchers spend most of their time conducting research, working on academic publications, and attending academic events, with far less time spent on non-academic outreach, events, and networks (academic and non-academic). Researchers report being most comfortable with plain language writing and, to a lesser extent, with collaborating with stakeholders; researchers are least comfortable interacting with media and reporters, finding and working with intermediaries to increase the impact of their work, and using technology to disseminate their research. Findings for each section of the conceptual framework are reported in more detail; researchers were asked to keep just one SSHRC-funded study in mind as they responded to the survey questions.

\section{Respondent Characteristics and Nature of Research}

Most (66\%) participants were female. Almost all researchers (91\%) had completed their $\mathrm{PhD}$ over 10 years ago, with $39 \%$ of this group having over 20 years of experience since completing their PhD. SSHRC grant values varied across the sample: a third (32\%) held grants valued between $\$ 50,000$ and $\$ 100,000,44 \%$ held grants valued between $\$ 101,000$ and $\$ 150,000$ and $24 \%$ held grants valued between $\$ 151,000$ and $\$ 200,000$. Our team inquired about whether their SSHRC project was connected to a larger research program: 34\% of respondents reported that their grant was part of a larger research program, with 33\% reporting additional funding from other sources including government sources outside SSHRC, internal university resources and other external organizations with interest in education.

Different types of research might be more amenable to mobilization efforts; consequently, researchers were asked to identify the nature of their research as practice-focused (59\%), basic conceptual research $(21 \%)$, policy-focused $(15 \%)$, or other $(5 \%)$. The sampling method could explain the dominance of practice-focused research since education was the explicit focus of the SSHRC grants held. Our team ran analyses in relation to demographic characteristics exploring years of experience, size of grants, as well as type of research; no significant differences were found; therefore, we do not report analyses in relation to demographic characteristics.

\section{Stakeholder Engagement}

Our team was interested in gauging what target audiences researchers perceived their work to be most relevant to (Table 2). 
Table 2. Reported relevance to different audience groups (from most to least relevant)

\begin{tabular}{|l|l|l|l|l|}
\hline & \multicolumn{4}{l}{ Relevance (\%) } \\
\hline \multicolumn{2}{|l|}{ Strong } & \multicolumn{2}{l|}{ Moderate } & \multicolumn{1}{l|}{ Slight } \\
\hline Audience & 72 & 12 & 9 & 8 \\
\hline Teachers & 54 & 22 & 17 & 7 \\
\hline Students & 44 & 29 & 12 & 15 \\
\hline School Boards & 39 & 29 & 16 & 16 \\
\hline $\begin{array}{l}\text { School Administrators (Principals, Vice } \\
\text { Principals Superintendents) }\end{array}$ & & & 18 & 15 \\
\hline $\begin{array}{l}\text { Educational Organizations (NGOs, think } \\
\text { tanks, advocacy groups) }\end{array}$ & 37 & 31 & 18 & \\
\hline Parents & 34 & 19 & 26 & 21 \\
\hline Government (Provincial or Federal) & 32 & 40 & 18 & 11 \\
\hline General Community & 21 & 31 & 34 & 14 \\
\hline Other & 50 & 10 & 0 & 40 \\
\hline
\end{tabular}

Researchers believe their work is relevant to a variety of stakeholders, with the dominant target audience being teachers ( $72 \%$ felt that their research was strongly relevant to teachers). In order of prominence, other target audiences for whom researchers perceived that their work mattered included students (54\%), school boards (44\%), school leaders (39\%), and educational organizations $(37 \%)$. Roughly a third of researchers believed their research was relevant to parents (34\%) and governments (32\%).

\section{How Often, and in What Capacities, Do Researchers Interact with End Users?}

Lavis et al. (2003) described ways that researchers interact with end users. This survey asked researchers how often researchers interacted with end users across different stages of the project (Table 3).

Table 3. Frequency of interaction with target audiences.

\begin{tabular}{|c|c|c|c|}
\hline \multirow[b]{2}{*}{ Type of Interaction } & \multicolumn{3}{|c|}{ Frequency of Interaction $\mathrm{n}(\%)$} \\
\hline & Regularly & Once/Twice & Not at all \\
\hline Making an effort to know target audience & 71 & 23 & 6 \\
\hline Discussing research results & 65 & 31 & 4 \\
\hline Discussing ideas beyond this project & 58 & 29 & 13 \\
\hline Discussing ideas arising from research & 57 & 33 & 10 \\
\hline Dedicated resources to capacity-building & 45 & 28 & 28 \\
\hline
\end{tabular}


The most frequent interactions with end users reported by researchers were (i) to make an effort to know their audiences regularly (71\%), and (ii) to discuss research results regularly $(65 \%)$. Over half of the sample also engaged regularly with target audiences to discuss ideas arising from the research (57\%) and to discuss ideas beyond the research project (58\%). Fewer researcher devoted dedicated interactions to capacity building with target audiences (45\%) with almost a third $(28 \%)$ not engaging in capacity building efforts with target audiences at all. Capacity building is known to be an underutilized (yet potentially powerful mechanism) to increase mobilization and uptake of research in policy and practice.

\section{Comparing the Proportion of Time Spend on Academic and Non-academic Outreach Activities.}

Due to rising expectations that researchers interact and collaborate with non-academic end users, the survey attempted to gauge the relative proportions of time spend on academic versus non-academic activities (Table 4).

Table 4. Proportion of time spent (out of $100 \%$ on specified KMb activities

\begin{tabular}{|l|l|l|l|l|l|}
\hline Variable & Mean & SD & Min (\%) & Max (\%) & $\begin{array}{l}\text { Interquartile } \\
\text { Range }\end{array}$ \\
\hline Conducting Research & 47 & 16.6 & 15 & 90 & $35-60$ \\
\hline Academic Publications & 26 & 14.4 & 5 & 100 & $20-30$ \\
\hline Non-academic Publications & 8 & 7.6 & 0 & 50 & $5-10$ \\
\hline Academic Events & 12 & 12.2 & 2 & 100 & $5-15$ \\
\hline Non-academic Events & 7 & 7.4 & 0 & 50 & $4.25-10$ \\
\hline Academic Networks & 4 & 3.5 & 0 & 10 & $0-5$ \\
\hline Non-academic Networks & 4 & 5.0 & 0 & 30 & $0-5$ \\
\hline
\end{tabular}

Researchers reported spending the largest proportion of time conducting research $(\mathrm{M}=47 \%$ of their time, SD=16.6). Questions about academic and non-academic outreach were asked in relation to three areas: publications, events, and networks. Academics reported spending far more time on academic publications $(M=26 \%$ of their time, $S D=14.4)$ than on nonacademic publications $(M=8 \%$ of their time, $S D=16.6)$. Hence, researchers spend more time on academic than on non-academic publications at a rate of 3:1. Researchers reported spending an average of $12 \%$ of their time on academic events $(\mathrm{SD}=12.2)$ and $7 \%(\mathrm{SD}=7.4)$ on non-academic events, a ratio of almost $2: 1$ in favour on academic events. Time spent on academic and non-academic networks was the same: academic networks $(M=4, S D=3.5)$ and non-academic networks $(M=4, S D=5.0)$. However, it is important to note (despite the empirical literature that suggests the importance of networks in bridging the divide between research, policy and practice), there is very low investments of researchers' time spent on networks. 


\section{How Prepared Do Researchers Feel to Engage in Different Types of Non-academic Outreach?}

The survey also asked researchers about how prepared researchers feel to engage in different types of non-academic outreach, such as creating plain language summaries, collaborating with stakeholders, interacting with media and reporters, finding and working with intermediaries, and using technology to disseminate research (Table 5).

Table 5. Researchers' perceived level of preparedness for non-academic outreach

\begin{tabular}{|c|c|c|c|c|c|}
\hline \multirow[b]{2}{*}{$\begin{array}{l}\text { Non-academic } \\
\text { Outreach } \\
\text { Activity }\end{array}$} & \multicolumn{5}{|c|}{ Level of preparedness } \\
\hline & $\begin{array}{l}\text { Very Well } \\
\text { Prepared } \\
(\%)\end{array}$ & $\begin{array}{l}\text { Prepared } \\
(\%)\end{array}$ & $\begin{array}{l}\text { Moderately } \\
\text { Prepared } \\
(\%)\end{array}$ & $\begin{array}{l}\text { Somewhat } \\
\text { Prepared } \\
(\%)\end{array}$ & $\begin{array}{l}\text { Not } \\
\text { Prepared } \\
(\%)\end{array}$ \\
\hline $\begin{array}{l}\text { Plain language } \\
\text { summaries }\end{array}$ & 54 & 23 & 14 & 7 & 3 \\
\hline $\begin{array}{l}\text { Collaborate with } \\
\text { stakeholders }\end{array}$ & 45 & 29 & 11 & 7 & 8 \\
\hline $\begin{array}{l}\text { Interact with } \\
\text { media and } \\
\text { reporters }\end{array}$ & 32 & 16 & 24 & 11 & 16 \\
\hline $\begin{array}{l}\text { Find and } \\
\text { work with } \\
\text { intermediaries }\end{array}$ & 22 & 16 & 29 & 12 & 21 \\
\hline $\begin{array}{l}\text { Use technology } \\
\text { to disseminate } \\
\text { research }\end{array}$ & 16 & 18 & 26 & 12 & 27 \\
\hline
\end{tabular}

There are very different skills involved in brokering and working with end-users (Cooper, 2013), so I was interested in how confident researchers felt engaging in these endeavours. Most researchers $(78 \%)$ felt prepared or very well prepared to write plain language summaries of their research. And a large percentage $(74 \%)$ also felt prepared or very well prepared to collaborate with stakeholders. However, fewer researchers felt prepared or very well prepared to interact with media (48\%), work with intermediaries $(38 \%)$ or use technology to disseminate research (35\%). Researchers felt the least prepared (38\% felt not prepared or only somewhat prepared) to use technology, close to a third felt not prepared or somewhat prepared to work with intermediaries $(33 \%)$ and, despite the prevalence of communications departments across 
universities, only $27 \%$ of researchers still felt not prepared or only somewhat prepared to deal with media and reporters about their research.

What Dissemination Mechanisms are Researchers Using in Education? Researchers were asked about three mechanisms to disseminate research arising from the literature: online strategies, media communications, and working with intermediary organizations. The use of online dissemination strategies was low with only $43 \%$ of researchers using websites, $15 \%$ using listservs, and fewer respondents using blogs $(3 \%)$ and social media (2\%). However, researchers were asked to think about a project that finished 5 years previously, so perhaps this is reflective of the fact that social media had not yet become as ubiquitous as it is now. .

Of the survey respondents, $47 \%$ indicated that their research is communicated through the media. The media picked the story up on its own in $62 \%$ of the cases. In just over half of the cases $(53 \%)$, the faculty's communication department contacted the media to initiate coverage, while only $15 \%$ of researchers contacted the media directly. Researchers reported sharing their findings in local and national newspapers and radio broadcasts, institutional media (e.g., faculty newsletter), or popular magazines (e.g., Today's Parent, Psychotherapy Networker).

One in four researchers $(25 \%)$ reported working with intermediary organizations to share their findings. Those that indicated they worked with intermediaries engaged in the following activities with these organizations in order of prominence: disseminated research through their networks (89\%), organized events based on research $(61 \%)$ provided professional development based on research results $(50 \%)$, created products based on research $(50 \%)$, facilitated interaction with a user group (44\%), partnered in research $(39 \%)$, disseminated research to the media $(28 \%)$.

\section{How Do Researchers' Perceive the Impact of Their Work?}

The survey asked researchers to report on the perceived impact of their work in four areas: research (e.g., expanded the current knowledge base), service (e.g., influenced practitioner behaviour, incorporated into professional development), policy (e.g., incorporated into an organizational or system level policy), and society(e.g., changed attitudes, improved outcomes) (Table 6).

Table 6. Perceived research impact on identified areas

\begin{tabular}{|l|l|l|l|}
\hline Area of Impact & Yes (\%) & No (\%) & Don't know (\%) \\
\hline Research & 76 & 3 & 21 \\
\hline Service (Practice) & 67 & 10 & 23 \\
\hline Policy & 35 & 28 & 38 \\
\hline Society & 35 & 23 & 42 \\
\hline
\end{tabular}

The primary area of impact was research, that is, advancing bodies of knowledge.. The second area of impact was service and practice. This area is often a focus of educational researchers, 
especially those who work with educational stakeholders such as teachers and principals. Researchers reported less impact in policy and the broader society; however, these were also the areas about which they expressed the greatest uncertainty about possible impact of their research.

Some researchers also provided short qualitative descriptions of each of these four areas of research impact (research $\mathrm{N}=36$; service/ practice $\mathrm{N}=31$; policy $\mathrm{N}=18$; society $\mathrm{N}=$ 14), and many researchers reported impacts spanning the four areas across one project. A researcher focusing on attention deficit hyperactivity disorder (ADHD) specified a number of perceived impacts:

KNOWLEGE: Understanding of children with ADHD for their own behaviours; peer victimization of children with ADHD; parent involvement in the education of children with ADHD; parenting stress in parents of children with ADHD; effectiveness of a mindfulness intervention for children and youth with learning disabilities and ADHD. SERVICE: Psychologists' understanding of limitations of self-report tools. Risk factors for peer victimization. CHANGED ATTITUDES \& IMPROVED OUTCOMES: Parent workshops served to change some of their attitudes and practices in relation to their children.

Other researchers talked specifically about evidence that showed the influence of their work that often involved consultations with government and policy-makers in the ministry, invitations to train practitioners, and involvement with a range of educational organizations working in their area:

Evidence of impact on knowledge base from invitations to contribute and to participate, queries from grad students, national \& international colleagues, government actors. Evidence of influence in the field from invitations to present to practicing educators and feedback on actions taken in consequence, for example, use of my PowerPoint presentations for teacher professional development. Evidence of societal impact from forms of recognition from outside organisations, such as awards, invitations to sit on community, foundation boards.

Another researcher described involvement in training teachers due to their research program:

Impacted directly on the participants, those who are directly involved in field teaching. Ongoing onsite and online programs have since been developed and have to date put through over a 1000 participants who are field teachers.

Some researchers even identified the various system levels or number of schools that had been influenced by their work: 
Role of parent involvement in early learning including home-school connections and family literacy interventions were promoted in Ministry initiatives (e.g. Best Start), in school boards (e.g. focus on parent involvement in early years), and in regional government (e.g. Region of Peel family literacy programs in approximately 80 schools as a result of research)

Many of the impact explanations also dealt with social justice issues:social justice curriculum, hiring policies for indigenous peoples, children with learning (dis)abilities, English-language learners (ELL), as well as work with specific groups (urban Inuit, Jewish communities, and marginalized youth).

Researchers also mentioned many barriers to research impact such as attribution (it is difficult in complex social systems to point to one factor, such as the research, as having impact), marginalization of various research topics, inconsistencies between research findings and the values of particular communities, and time lag between conducting and disseminating research and its subsequent influence in communities:

My work is just now being sent out as this is a longitudinal study. My grant has finished but I am just now putting out the findings. My answers could change in a year or two but it is too soon to tell.

The correlation between time and impact is important; literature suggests that impact can take years to infiltrate public services (Nutley et al., 2007).

These descriptions show tangible benefits that Canadian researchers are having as a result of their interaction with different educational stakeholders and communities.

\section{Discussion}

Lavis (2006) outlines five types of activities used to increase evidence use in policy, including prioritization and coproduction, packaging and push, facilitating pull, exchange, and improving climate/ building demand. The discussion explores each of these areas in relation to the findings to provide suggestions and implications for the field of education.

\section{Prioritization and Co-production}

There is emerging evidence to suggest that involving end-users at the outset of the project, rather than passive participants, can improve the demand and use of research (Cherney, Head, Povey, Boreham, \& Ferguson, 2015; Cherney, Povey, Head, Boreham, \& Ferguson, 2012; Phipps \& Shapson, 2009). Educational researchers reported regular interaction to get to know target audiences, and noted that their research had strong relevance for teachers. Brett et al. (2012), from a study in the health sector, show positive impacts from collaboration being identified at four stages of the research process: planning the research, undertaking the research, analyzing and writing up the study, and disseminating the research and considering its implications. In the end, they found "clear evidence that [end-user] and public involvement can have positive 
impacts on research, enhancing the quality of research and ensuring its appropriateness and relevance" (p. 643). In education, while researchers report involving stakeholders once the study has been funded, very few discussed having involved educational stakeholders in setting the research priorities and questions in the first place. Having communities and end-users involved prior to the conceptualization of the study is important, as it can actually create demand for the findings since the topic itself was generated by the practitioner community. In this way, knowledge mobilization and engaged scholarship, rather than being a top-down process, becomes a collaborative mechanism for communities and teachers to solve particular problems of practice. Phipps et al. (2016) describe how coproduction models of research impact actually have the potential to accelerate or even skip some of the more traditional stages of research utilization (such as dissemination, uptake and implementation) because the end users are actually involved at the beginning and hence uptake occurs through the collaboration embedded throughout the course of a project, rather than occurring terminally after the project is already completed:

Knowledge mobilization is often described using the metaphor of "bridging the gap" between the silos of research and policy/practice; however, this metaphor maintains the academic and non-academic silos. In co-production there is no gap to bridge. Academic researchers and non-academic partners come together in a shared space of collaboration (see Figure 2). They maintain their own independent spaces but research, dissemination, uptake, and implementation occur in a collaborative environment. (p.37)

Involving stakeholders in co-production and prioritization of research topics is a fundamental shift from traditional notions of research controlled by academics towards a more iterative and fluid process that seeks to influence and benefit communities. In this dynamic process, traditional research outputs (such as academic journal articles laden with dense jargon) must also be reimagined.

\section{Packaging and Push}

Literature on $\mathrm{KMb}$ and the lack of use of research by end-users has long lamented the inaccessible format of research articles and reports (Cooper, Klinger, \& McAdie, 2017; Davies, Nutley, \& Walter, 2005; Levin, Cooper, Arjomand, \& Thompson, 2011). Researchers in this study reported low levels of use of media, online dissemination tools, and low levels of interaction with intermediaries that could be active $\mathrm{KMb}$ agents with various target audiences. Educational researchers also reported a lack of confidence engaging with media and reporters, online tools, and intermediaries. However, the gap between research and practice has been attributed to both the packaging of research, which is not useful to end-users, as well as the passive push mechanisms used by academics. Publishing a journal article or posting a report on a website remains insufficient to increase research use on the frontlines. There is now growing recognition that research needs multiple modalities and engaging outputs in order to

Engaged Scholar Journal: Community-Engaged Research, Teaching, and Learning 
be useful to policy-makers and practitioners, and products need to be tailored to the different target audience (for instance, policymakers' needs are very different than practitioners' needs). Similarly, push mechanisms need to integrate ways that actually reach end-users through a combination of efforts that recognizes the primary sources of professional knowledge in different fields. For some end-users, social media and twitter will be useful; for teachers, dissemination through unions and professional association e-bulletins and publications is more likely to be successful than academic journals residing behind a paywall. However, just relying on push mechanisms will also not produce the robust research integration that can change public service delivery; it is also important to create mechanisms that allow end-users to search and pull information that they need into their practice environments.

\section{Facilitating Pull}

Facilitating pull is about creating brokering structures to assist busy policymakers and practitioners apply research in focused and time sensitive ways. However, only one in four educational researchers was interacting with intermediary organizations that might facilitate pull for different end users. Unlike researchers 'pushing' mobilization products, 'pull' mechanisms put users at the center of the process, as it is users who drive the search, adaptation, and implementation of research based policies, processes, and practices. Emerging findings from studies in education are emphasizing that to facilitate pull and focus on the need of practicing teachers, research mobilization efforts need to be embedded in school and district level processes (Coburn \& Turner, 2011; Datnow \& Hubbard, 2016; Honig \& Coburn, 2007). Campbell and Levin (2012) highlight that teachers and educational leaders need to be able to find, understand, share, and act on research and that intermediaries are well situated to mediate processes between research producers and users. Each of these four steps (find, understand, share, and act) requires different efforts on the part of researchers, mediators, and practitioners. For instance, research needs to be publically available in ways that educators can sift and search according to their needs. In the health sector, databases of research with plain language summaries and implications for different stakeholders have been created to facilitate these efforts. In the United Kingdom, the Education Endowment Foundation (EEF) is an intermediary educational organization that has created a searchable database for education that provides synthesis of evidence in particular areas, outlines the strength of that evidence, and includes the cost of particular interventions or initiatives (https://educationendowmentfoundation.org.uk/resources/teaching-learning-toolkit). However, the EEF has a large budget of over $\$ 20$ million per year; hence, creating these types of databases that focus on end-users is not cheap. This database has already had widespread use, with recent surveys noting that "two-thirds of schools now use it to inform their teaching practice and spending decisions" (Education Endowment Foundation, 2016). The fact that two-thirds of schools are now using the toolkit since its inception in 2012 is quite a remarkable achievement, especially considering the traditionally low use of research usually reported in educational contexts globally. So, there are models that show the type of mechanisms that could help users meet the challenges of their professional contexts, such as interactive toolkits 
that provide multi-media training and implications for teachers on the frontlines. Another mechanism critical to increasing research mobilization and engaged scholarship is the two-way exchange of information and expertise between end-users and researchers.

\title{
Exchange
}

Research-informed practice is the mantra in education currently; however, what about the role of practice-informed research? Reciprocity between research users and producers is important so that community members, policymakers, and practitioners are more than just research subjects. Once again, while intermediaries can facilitate interaction among diverse stakeholders, researchers in this study were not utilizing them to amplify their messages with specific end-users. The Economic and Social Research Council (ESRC) (2009) in the UK, commissioned a series of impact case studies in order to identify impacts of funded research on policymakers, professional practitioners, and other groups outside academia, analyze determinants of impact, and develop suitable approaches to impact assessments in the social sciences. Ultimately, they found that engaged scholarship remains central to creating impact:

\begin{abstract}
In all the impact case studies, the most important factor contributing to the generation of impact was the pre-existence of networks and relationships with research users. Sustained contacts with users, based on personal relationships and built up over the long term were the most important channels for policy and practice applications. Evaluators commented that the ideal connectivity with users was a two way process, where research findings were fed into policy and practice arenas, whilst pertinent policy and practice issues could inform the development of new research ideas. Early and continuous engagement with users at various stages of the research (from design through to dissemination) could help to increase the relevance and accessibility of research findings and increases the probability of impact. (p. 15)
\end{abstract}

This report highlights the need for exchange and two-way flow of information between producers and users. While many initiatives attempt a one-way transmission from research to policy and/or practice, very few mechanisms seek to use policy and practice settings in order to inform the research enterprise. There is also evidence to suggest that a key determinant in whether or not a practitioner will use research (and the frequency of that use) is whether or not they have had collaborative experiences participating in research projects (Belkhodja, Amara, Landry, \& Ouimet, 2007). So, a focus on exchange and collaboration could contribute to further build practitioners' appetite for evidence use. In addition to exchange between producers and users, it is successful collaborations that have the potential to improve the climate of research use more broadly in public services and build demand for research within our educational systems.

\section{Improving Climate and Building Demand}

Because practitioners view academic research as irrelevant to their contexts, they have not 
demanded research, although much is consistently produced by universities. There is too large a gap between academic research production and the needs of frontline policymakers and practitioners. A famous saying by Peter Drucker- “culture eats strategy for lunch"—points out the power of organizational culture. For research to be integrated into the frontlines of service delivery in public service sectors, the climate of schools and districts needs to be transformed to build demand, interest, and appetite for evidence-use and research. Many of the actions already discussed would improve the climate and culture of research use in education: building stronger relationships between users and producers, involving end-users in prioritization and co-production of research topics and projects, changing packaging and push mechanisms with the end-user in mind, facilitating pull mechanisms for busy professionals, and increasing opportunities to have meaningful exchange of expertise and ideas among producers and users. Building a strong research culture takes time, and one of most crucial, and currently least attended to, necessary actions is to build the capacity of practitioners, educational leaders and policy makers to use data to actually implement evidence-based practices (Datnow \& Hubbard, 2016; Gough, Tripney, Kenny, \& Buk-Berge, 2011). To change culture, $\mathrm{KMb}$ infrastructure needs to be embedded at the organizational level in schools and school districts, so that research and data use is seen by frontline practitioners as a tool to solve the many challenges that schools, communities, and students face daily.

\section{Limitations}

This study had several limitations including small sample size, lack of prior research studies on the topic, and self-reported data. The primary limitation was its small sample size; more participants are needed to make generalizations regarding the data, although the data still provides a snapshot of how researchers in education are engaging with end-users and how they perceive the impact of their work. Ideally, the sample would be more evenly distributed across gender ( $66 \%$ of respondents were women). Also, data were not triangulated, which could have been partially addressed by adding qualitative interviews or case studies of impact bounded by projects in which researchers perceived high impact; however, due to the anonymity of the survey, we could not sample based on participant responses. Another way to triangulate research impact data would be to survey the end-users that researchers engaged with as well, to see how they perceived the impact of a particular project. However, this approach would also yield very small samples in most cases. Another limitation of the study is that data from the survey relies on self-reporting. Self-reported data from researchers can rarely be independently verified and could contain many biases including attributing more impact to a project than actually occurred or than end-users would perceive.

\section{Conclusion}

This article presented empirical research on how SSHRC-funded education researchers across Canada are interacting with end users and perceiving the impact of their work, an area where there is still a dearth of empirical evidence. Educational researchers are engaging with stakeholders, and involving them in a range of activities, although capacity-building efforts 
with end users remain underdeveloped. While researchers feel comfortable writing plain language summaries, less than half of the researchers in this study felt 'very well prepared' to collaborate with stakeholders, and even less felt comfortable working with intermediaries to amplify their message or using technology to disseminate their work. As a result, there are many areas in which $\mathrm{KMb}$ efforts could be improved both on the research production side (through researchers developing more robust partnerships with intermediaries and end users) and on the research use side (through mechanisms to allow practitioners to find, understand, share, and apply research).

Table 7. Recommendations

\begin{tabular}{|c|c|}
\hline Activity & Recommendations \\
\hline Prioritization and coproduction & $\begin{array}{l}\text { - Including end-users in conceptualizing research } \\
\text { project and questions, including } \\
\text { - practitioners and community members as co- } \\
\text { investigators rather than just participants }\end{array}$ \\
\hline Packaging and push & $\begin{array}{l}\text { - Creating non-academic formats of research } \\
\text { that are relevant to end-users with a focus } \\
\text { on actionable messages for practitioners and } \\
\text { educational leaders } \\
\text { - Working with partners to create outputs to } \\
\text { ensure relevance to end-users } \\
\text { - Have end-users involved in distribution of } \\
\text { resources to increase credibility and uptake }\end{array}$ \\
\hline Facilitating pull & $\begin{array}{l}\text { - Using trusted intermediaries (organizations that } \\
\text { translate research to practice and already have } \\
\text { established networks) } \\
\text { - Creating feedback loops for practitioners to } \\
\text { request research on topics they are interested in } \\
\text { and that can inform the current challenges they } \\
\text { are facing (rapid response policy units, research } \\
\text { infrastructure embedded in districts) }\end{array}$ \\
\hline Exchange & $\begin{array}{l}\text { - Too often exchange is thought of directionally } \\
\text { from research to practice; however, practice- } \\
\text { informed research is also important as it } \\
\text { recognizes flow from the frontlines and } \\
\text { practitioner knowledge back into research } \\
\text { processes }\end{array}$ \\
\hline
\end{tabular}




\begin{tabular}{|l|l|}
\hline $\begin{array}{l}\text { Improving climate/ building } \\
\text { demand }\end{array}$ & $\begin{array}{l}\text { Building an evidence-informed culture in } \\
\text { schools by integrating research knowledge into } \\
\text { professional development }\end{array}$ \\
$\qquad \begin{array}{l}\text { Organizing events that invite researchers and end- } \\
\text { users to collaborate so that end users can identify } \\
\text { relevant problems of practice for researchers to } \\
\text { pursue. }\end{array}$ \\
\hline
\end{tabular}

What is clear is that research is having many impacts on research and practice in education and, to a lesser extent, policy and society at large. Researchers are taking on important projects, many of which address important equity issues in marginalized communities, so the potential to increase these efforts through $\mathrm{KMb}$ can only act to further strengthen our education systems in Canada. Researchers were positive about their interaction with diverse educational stakeholders, and it is through continued building of trust and reciprocal and substantive partnerships that system improvements will occur. Engaged scholarship is gaining recognition and momentum in academia. While it is challenging, expensive, and sometimes slow work to build substantive partnerships, efforts to build those networks will ultimately provide stronger connections among publicly funded research and public service sectors to the benefit of Canadian citizens.

\section{Acknowledgements}

This study was a SSHRC funded study (Principal Investigator: Dr. Ben Levin) conducted by the former Research Supporting Practice in Education program at the Ontario Institute for Studies in Education, University of Toronto.

\section{About the Author}

Amanda Cooper, Assistant Professor in Educational Leadership and Policy at Queen's University, is the founder of RIPPLE (Research Informing Policy, Practice and Leadership in Education): a program of research, training and knowledge mobilization ( $\mathrm{KMb}$ ) aimed at learning more about how knowledge brokering can increase research use and its impact in education by facilitating collaboration between multi-stakeholder networks. Email: amanda. cooper@queensu.ca 


\section{References}

Belkhodja, O., Amara, N., Landry, R., \& Ouimet, M. (2007). The extent and organizational determinants of research utilization in Canadian health services organizations. Science Communication, 28(3), 377-417.

Bowen, S. J., \& Graham, I. D. (2013). From knowledge translation to engaged scholarship: Promoting research relevance and utilization. Archives of Physical Medicine and Rehabilitation, 94(1), S3-S8.

Boyer, E. L. (1990). Scholarship reconsidered: Priorities of the professoriate. New York: Carnegie Foundation for the Advancement of Teaching.

Brett, J., Staniszewska, S., Mockford, C., Herron-Marx, S., Hughes, J., Tysall, C., \& Suleman, R. (2012). Mapping the impact of patient and public involvement on health and social care research: A systematic review. Health Expectations, 17(5), 637-650.

Campbell, C., \& Levin, B. (2012). Developing knowledge mobilisation to challenge educational disadvantage and inform effective practices in England. London: Education Endowment Fund.

Cherney, A., Head, B., Povey, J., Boreham, P., \& Ferguson, M. (2015). The utilisation of social science research - The perspectives of academic researchers in Australia. Journal of Sociology, 51(2), 252-270.

Cherney, A., Povey, J., Head, B., Boreham, P., \& Ferguson, M. (2012). What influences the utilisation of educational research by policy-makers and practitioners?: The perspectives of academic educational researchers. International Journal of Educational Research, 56, 23-34.

Coburn, C. E., \& Turner, E. O. (2011). Research on data use: A framework and analysis. Measurement, 9, 173-206.

Cooper, A. (2013). Research-brokering organizations in education across Canada: A response to evidence-based policy-making and practice initiatives. In S. Young (Ed.), Evidence-based policy making in Canada (pp. 67-92). Toronto: Oxford University Press.

Cooper, A., Klinger, D. A., \& McAdie, P. (2017). What do teachers need? An exploration of evidence-informed practice for classroom assessment in Ontario. Educational Research, 1-19.

Cooper, A., Levin, B., \& Campbell, C. (2009). The growing (but still limited) importance of evidence in education policy and practice. Journal of Educational Change, 10, 159-171.

Cuthill, M. (2010). Working together: A methodological case study of "engaged scholarship." Gateways: International Journal of Community Research and Engagement, 3, 20-37.

Datnow, A., \& Hubbard, L. (2016). Teacher capacity for and beliefs about data-driven decision making: A literature review of international research. Journal of Educational Change, 17, 7-28.

Davies, H., Nutley, S., \& Walter, I. (2005). Approaches to assessing the non-academic impact of social science research. In Report of the ESRC symposium on assessing the non-academic impact of research 12th/13th May 2005 (pp. 1-33). London: Research Unit for Research Utilisation. Retrieved from http://www.ruru.ac.uk/pdf/ESRCImpactSymposiumFinalReport040705.pdf

Davies, H. T. O., Nutley, S. M., \& Smith, P. C. (2000). What works? Evidence-based policy and practice in public services. Bristol, United Kingdom: Policy Press.

Economic \& Social Research Council (ESRC). (2009). Taking stock: A summary of ESRC's work to evaluate the impact of research on policy and practice. Swindon, UK: ESRC. Retrieved from http:/ / www.esrc.ac.uk/_images/Taking Stock_tcm8-4545.pdf

Edelstein, H., Shah, S., \& Levin, B. (2012). Mining for data: Assessing the use of online research. International Journal of Humanities and Social Science, 2(9), 1-12.

Engaged Scholar Journal: Community-Engaged Research, Teaching, and Learning 
Education Endowment Foundation. (2016). Retrieved from https://educationendowmentfoundation. org.uk

Eisenhart, M. A., \& Howe, K. R. (1992). Validity in educational research. In M. D. LeCompte, W. L. Millroy, \& J. Preissle (Eds.), The handbook of qualitative research in education (1st ed., pp. 642680). San Diego, CA: Academic Press.

Garner, P., Kale, R., Dickson, R., Dans, T., \& Salinas, R. (1998). Implementing research findings in developing countries. BMJ, 317(7157), 531-535.

Gough, D., Tripney, J., Kenny, C., \& Buk-Berge, E. (2011). Evidence informed policymaking in education in Europe. EIPEE Final Project Report Policy Brief. London: University of London. Retrieved from http://www.eipee.eu/

Hemsley-Brown, J. (2004). Facilitating research utilisation: A cross-sector review of research evidence. International Journal of Public Sector Management, 17(6), 534-552.

Hicks, D. (2012). Performance-based university research funding systems. Research Policy, 41(2), 251261.

Honig, M. I., \& Coburn, C. (2007). Evidence-based decision making in school district central offices: Toward a policy and research agenda. Educational Policy, 22(4), 578-608.

Jacobson, N., Butterill, D., \& Goering, P. (2005). Consulting as a strategy for knowledge transfer. The Milbank, Quarterly, 83(2), 299-321.

Kitson, A., Harvey, G., \& McCormack, B. (1998). Enabling the implementation of evidence based practice: A conceptual framework. Quality in Health Care, 7(3), 149-158.

Kittleson, M. J. (1995). An assessment of the response rate via the postal service and e-mail. Health Values: The Journal of Health Behaviour, Education and Promotion, 19(2), 27-39.

Knott, J., \& Wildavsky, A. (1980). If dissemination is the solution, what is the problem? Science Communication, 1(4), 537-578.

Kuruvilla, S., Mays, N., Pleasant, A., \& Walt, G. (2006). Describing the impact of health research: A research impact framework. BMC Health Services Research, 6, 1-18.

Landry, R., Amara, N., \& Lamari, M. (2001). Utilization of social science research knowledge in Canada. Research Policy, 30(2), 333-349.

Lavis, J. (2006). Research, public policymaking, and knowledge-translation processes: Canadian efforts to build bridges. J Contin Educ Health Prof. 26(1).

Lavis, J. N., Robertson, D., Woodside, J. M., McLeod, C. B., \& Abelson, J. (2003). How can research organizations more effectively transfer research knowledge to decision makers? The Milbank Quarterly, 81(2), 221-248.

Lemieux-Charles, L., \& Champagne, F. (2004). Using knowledge and evidence in health care: Multidisciplinary perspectives. Toronto: University of Toronto Press, Scholarly Publishing Division. Retrieved from http://www.jstor.org/stable/10.3138/9781442682979

Levin, B., Cooper, A., Arjomand, S., \& Thompson, K. (2011). Can simple interventions increase research use in secondary schools? Canadian Journal of Educational Administration and Policy, (126), 1-29. Retrieved from https://www.umanitoba.ca/publications/cjeap/

Martin, S. (2010). Co-production of social research: Strategies for engaged scholarship. Public Money \& Management, 30(4), 211-218. http://doi.org/10.1080/09540962.2010.492180

Mitton, C., Adair, C. E., Mckenzie, E., Patten, S. B., \& Perry, B. W. (2007). Knowledge transfer and exchange: Review and synthesis of the literature. The Milbank Quarterly, 85(4), 729-768. 
Muirhead, B., \& Woolcock, G. (2008). Doing what we know we should: Engaged scholarship and community development. Gateways: International Journal of Community Research and Engagement, 1, 8-30.

Nutley, S. M., Walter, I., \& Davies, H. T. O. (2007). Using evidence: How research can inform public services. Bristol, UK: Policy Press. Retrieved from http://press.uchicago.edu/ucp/books/book/ distributed/U/bo13441009.html

Paynter, S. (2014). Tackling wicked problems through engaged scholarship. Journal of Community Engagement and Scholarship, 7(1). Retrieved from http://jces.ua.edu/tackling-wicked-problemsthrough-engaged-scholarship/

Pfeffer, J., \& Sutton, R. I. (1999). The knowing-doing gap: How smart companies turn knowledge into action. Boston: Harvard Business School Press. Retrieved from https://hbr.org/product/theknowing-doing-gap-how-smart-companies-turn-knowledge-into-action/1266KB-KNDENG

Phipps, D., Cummings, J., Pepler, D., Craig, W., \& Cardinal, S. (2016). The co-produced pathway to impact describes knowledge mobilization processes. Journal of Community Engagement and Scholarship, 9(1), 31-40.

Phipps, D. J., \& Shapson, S. (2009). Knowledge mobilisation builds local research collaborations for social innovation. Evidence \& Policy: A Journal of Research, Debate and Practice, 5(3), 211-227.

Saija, L. (2014). Writing about engaged scholarship: Misunderstandings and the meaning of "quality" in action research publications. Planning Theory \& Practice, 15(2), 187-201.

Sheldon, T. A., Guyatt, G. H., \& Haines, A. (1998). Getting research findings into practice: When to act on the evidence. BMJ, 317(7151), 139-142. http://doi.org/10.1136/bmj.317.7151.139

SSHRC. (2014). Knowledge mobilization. Retrieved June 15, 2014, from http://www.sshrc-crsh. gc.ca/society-societe/community-communite/index-eng.aspx\#2

Walter, I., Nutley, S., \& Davies, H. (2003). Developing a taxonomy of interventions used to increase the impact of research. St. Andrews, United Kingdom: Research Unit for Research Utlisation, Department of Management, University of St. Andrews. Retrieved from http://www.ruru. ac.uk/pdf/Taxonomy development paper 070103.pdf

Weiss, C. (1979). The many meanings of research utilization. Public Administration Review, 39(5), 426431.

Wixted, B., \& Beaudry, C. (2012). “Capturing the impacts" of research: Discussion paper. Ottawa, Ontario. Retrieved from http://publications.gc.ca/site/eng/445230/publication.html 